\title{
A Development of MALL Materials to Quality Education and Support English Oral Communicative Learning of Thai Airport Immigration Police Officers
}

\author{
Yujiao Zhang* \\ Faculty of Education, Chulalongkorn University, Bangkok, Thailand
}

\begin{abstract}
Mobile-assisted language learning (MALL) creates more opportunities for learners to access learning resources more easily and selfdirectly without time and place limitation. Thus, this study aimed at developing MALL materials to support the English oral communicative learning of Thai airport immigration police officers based on needs analysis and exploring the quality of MALL materials to support English oral communicative learning of Thai Airport Immigration police officers. The instruments of this study were the semi-structured interviews with the officers in order to conduct needs analysis, and the IOC (Item-Objective Congruence) form for experts to validate the materials developed, and the questionnaire to assess the officers' opinions after using the materials to explore the quality. ADDIE model was applied to guide the overall process of developing the materials. The findings indicated that the self-instructional MALL materials laded in WeChat public platform that consisted of two units, Arrival and Departure, and ten lessons that were under each unit, both of which were accordance with the airport immigration officers' needs. Moreover, the evaluation based on the officers' opinions revealed that the MALL materials had high quality of content, rational organization, pleasant presentation and convenient functions of the platform.
\end{abstract}

\section{Introduction}

Being a common lingua franca across the world today, English plays a significant role in the global level of international communication. Most ELF interactions take place among 'nonnative' speakers of English [1]. In Thailand, the role of English, particularly the oral skills are necessary for job employment, international communication and economic competition. As a popular tourist destination, the number of tourist arrivals in Thailand is steadily increasing with 29.88 million in 2015, which is double in this decade compared to last decade. Moreover, Chinese visitors are now the biggest source of visitors and expenditure, which generated 376 billion baht in revenue and up 88\% from 2014 [2]. Due to the sharp rise in Chinese visitor expenditure, there is an urgent need to improve the services of the front-line executors who are the Thai airport immigration police officers, of which the English

*Corresponding author: zyjhandy@163.com 
proficiency is deficient when communicating with Chinese speaking passengers at work, thus lead to a lot of misunderstandings and difficulties.

Without any specified English language learning materials to support the airport immigration officers' oral English proficiency, while with pressing needs of improving their English oral communicative learning to deal with daily work, there is a big gap between the reality and target that should be bridged with an appropriate solution. Adult learners, according to Knowles [3], were self-directed human being. With individual preferences of learning styles, content and other relevant aspects, self-instruction is with adults' selfdirected learning or self-study, which can be acquired by themselves and with their own pace [4]. In self-instruction, learners learn with their own pace, method and attempt to create action to serve personal individual needs and skills [5]. Therefore, specially produced selfinstructional materials that suit the learning needs and the background knowledge of officers will definitely inform about the target language, stimulate language use or help to make discoveries about the language for themselves $[6,7]$.

What's more, technology enables learners to have more opportunities to access varies language learning recourses, and M-learning happens when the learners are not at a fixed location, or learning that happens when the learners make use of the learning chances offered by the portable mobile devices, whenever and wherever the learners can learn by using mobile devices [8]. Mobile technologies possess the features of flexibility, low cost, small size and user-friendliness, thus researchers are exploring how to use mobile technologies to support language learning in practice [9]. Therefore, applying Mobile-assisted language learning that combine with self-instructional materials based on needs analysis of the target learners can be a workable solution. The Micro-propagation platform WeChat has been proved to enhance oral language learning, activated learners' interests and enhanced the language teaching and learning efficiency undoubtedly [9], which is suitable for developing the MALL materials for the current study.

Developing language learning materials can be in line with the common instructional materials model, ADDIE model, which consist of Analyze, Design, Implement, and Evaluate [10]. Considering the communication difficulties were mutually from both the officers' English language deficiency and the Chinese passengers' pronunciation features, it's not evitable to review the distinctive English pronunciation features spoken by Chinese speakers. Based on Deterding [12], there are three main features that represent the English pronunciation features spoken by Chinese: 1) Syllable structures: an extra schwa is usually inserted after final plosive or within a consonant; 2) Vowels and diphthongs: no contrast between long and short vowels; 3) Consonants: long and short vowels couldn't be differentiated and substituted instead. Thus, by synthetically considering these features into self-instructional MALL materials development, the ultimate goals of the officers can be achieved from all angels.

\section{Objectives}

The objectives of the present study were as follows:

- To develop MALL materials to support the English oral communicative learning of Thai airport immigration police officers;

- To explore the quality of MALL materials by validating the materials with Item-Objective Congruence (IOC) method and surveying the officers' opinions of the materials after using. 


\section{Methodology and research design}

There were 5 stages that in the ADDIE model in the process of developing the MALL materials to support the English oral communicative learning of Thai airport immigration officers, which were as follows:

Stage 1 - Analysis: exploring the needs, goals and expectations of Thai airport immigration police officers' English language use at work by conducting semi-structured interviews;

Stage 2 - Design: applying both language and learning theories into writing design of the MALL materials based on needs analysis to specify the learning objectives, content, tasks and assessment.

Stage 3 - Development: Materials validation. In this process, three experts were invited to evaluate the designed materials about the quality, the organization, the presentation of the materials, the use of materials in the public platform, and the appropriateness of the recordings by using the IOC (Item-Objective Congruency) method. Two sample lessons laded in WeChat Public Platform were offered for validation.

Stage 4 - Implementation: piloting the materials developed by distributing the materials to a small group of officers to experience and getting feedback from them, which aimed at consistently analyzing and enhancing the developed learning materials to ensure the effective delivery and designing evaluation for exploring the quality of the materials.

Stage 5 - Evaluation: evaluating the quality and effectiveness of the MALL materials by conducting questionnaire survey about the officers' opinions after using the materials.

\section{Population and participants}

In the first stage of exploring the needs of the immigration officers at Don Muang International Airport by qualitative research method, there were 24 immigration officers who had taken the semi-structured interviews, 2 of which is the superintendent, 12 of which were the supervisors from arrival and departure section, and 10 of which were officers from overstaying office. In the third stage of developing the materials after designing, 3 experts from ELT field conducted the Item-Objective Congruence (IOC) method to validate the MALL materials. In the fifth stage of evaluating the MALL materials, 8 inspectors and 50 supervisors of Arrival Section and Departure Section, and 10 officers of Overstay office were involved in the questionnaire survey that aimed at probing into the immigration officers' opinions of the MALL materials after using.

\section{Instruments}

There were three types of instruments. The first was the semi-structured interview that applied as the quantitative research method to explore the participants' target needs, which were necessities, lacks and wants [12]. The second was the Item-Objective Congruence (IOC) form that used to validate the MALL materials by three experts from ELT field. The third was the validated MALL materials together with questionnaire forms that exerted as the quantitative research method to probe into the participants' opinions of the materials after using.

\subsection{Semi-structured interview}

The semi-structured interview consisted of 2 parts. Part I was General information about the participants' name, gender, age, position, educational background, working experience and 
contact information. Part II contained 13 questions that aimed at exploring the participants' needs of using English, which were corresponding to necessities, lacks and wants about the participants' English language use at work, situations, difficulties and preferences about learning English language for duty purposes.

\section{$5.210 \mathrm{C}$ form}

The IOC form included 18 items that aimed at validating the content of the MALL materials developed concerning to the quality, the organization, and the presentation of the content, the use of the materials in the public platform in WeChat and the appropriateness of the recordings. Three experts from ELT field were invited to validate the MALL materials based on the criteria above by rating the level of appropriateness with " +1 ", " 0 " or " -1 ". " +1 " meant "the item is appropriate to be used, " 0 " meant "I am not sure" and "- 1 " meant "the item is not appropriate to be used". The mean score $\bar{x}$ was applied to assess the results. The items that obtain the IOC $\bar{x}$ from 0.5 to 1.0 were considered acceptable.

\subsection{Questionnaire}

The questionnaire was adapted from Kumar's (2010) "Evaluation criteria for preparation and evaluation of self-instructional materials", which consisted of 2 parts: Part I General information about the participants' gender, age, educational background, position and working experience; Part II was 20 statements that consisted of 4 parts, the quality, the organization, the presentation of the content, and the use of the materials. In part II, fiveLikert scale was applied to assessing the participants' opinions toward the MALL materials after using. 5 meant "Strongly agree" and 1 meant "Strongly disagree". From 5 to 1, the degree of agreement decreased orderly.

\section{Data collection}

Three types of data collection were specified. The 1 st was the information from the face-toface interviews with the officers. The 2 nd was the content validity check results from the IOC method by experts. The 3rd was the data from the questionnaires to evaluate the materials by the officers.

\section{Data analysis}

In order to develop the MALL materials concerning to the all components that should be covered, the qualitative method, namely the semi-structured interviews were conducted with the participants to explore the needs of English language use at work, of which the content analysis was interpreted to scope the materials that involved all the components. Moreover, for the sake of validating the content of the materials and assessing the participants' opinions of the materials after using, the quantitative data from the IOC forms and questionnaires were calculated by applying mean score $\bar{x}$ in order to evaluate the quality of the self-instructional MALL materials.

\section{Findings}

There were 5 main parts that revealed the findings based on the objectives of this study, which are needs analysis, translating needs into materials design, instructional manual 
development, materials validation and implementation and evaluation of the materials, all of which were as follows.

\subsection{Needs analysis}

According to the semi-structured interviews, of which the part of questions are offered in Chart 1 , the results were as follows:

There were around 80 officers involved inspectors, supervisors and officers from Arrival and Departure Section who had high needs of improving English proficiency. The main tasks of police officers of Exit-Entry ports at the airport were arrival and departure formalities.

English language was mainly used orally in:

- checking passengers' documents;

- inquiring passengers' general information;

- giving guidance and help to passengers;

- informing the passengers' visa types, dwell time and overstaying;

- identifying the passenger's overstaying;

- guiding passengers to pay the fine of over-staying;

- affirming the passengers' over-staying;

- persuading and warning the passenger to pay the fine.

English speaking and listening skills were deficient especially in vocabulary, expression and conversation use, which were both from their own sake and the Chinese speaking passengers' varied English proficiency in pronunciation. Thus, quite a few misunderstandings were aroused between them, which resulted in the failure of oral communication. These misunderstandings were mainly caused by the deficiency of work-related vocabulary and expressions, pronunciation differences, communication manners, lack of confidence to speak English.

In regard to the content they concerned about the learning materials, the frequently used words, expressions and daily conversation that highly related with working situations would be effective for their duty use. An appropriate amount of pointed and interesting exercise with feedback would be practical. Moreover, the common pronunciation features of English spoken by Chinese speakers were also required. Being interested in and inspired by using mobile devices to learn English language, the participants desired that the mobile device application should be free to use, easy to control and friendly to follow if offered.

Table 1. Part of the interview questions

\begin{tabular}{|l|}
\hline Sample Question Items \\
\hline What is your current position? \\
\hline What are your duties? \\
\hline In what situations do you need to use English? \\
\hline What difficulties do you have when you use English? Can you give some examples? \\
\hline Why do you want to improve your English if you think you need? \\
\hline $\begin{array}{l}\text { What English language skills do you want to improve most concerning to your work, like } \\
\text { reading, listening, speaking or writing? }\end{array}$ \\
\hline $\begin{array}{l}\text { What learning content would be suitable if you will be offered with English learning materials } \\
\text { concerning to your work? }\end{array}$ \\
\hline What kind of study pattern would be convenient for you? \\
\hline
\end{tabular}


What do you desire if you will be offered learning materials that you can study on your phone?

What kind of exercise would you like to do when you study the materials?

\subsection{Translating needs analysis to materials design}

According to the officers' requirements, only oral English skills, namely, speaking and listening were frequently used in communication at work. Therefore, this study aimed at supporting the English oral communicative learning by developing materials to meet the needs. Since there was no specific English learning materials development for supporting English oral communicative learning of the airport immigration officers, the main situations, namely arrival inspection, departure inspection and overstaying disposal were involved to design the learning materials.

Based on Communicative Language Teaching, the communication, task and meaningfulness principles are with the activities design in developing the learning materials. Real communications, meaningful tasks and language engage the learners in meaningful and authentic language use $[13,14]$. Thus, by combining principles with the target learners' needs, which required that English as a means of expression about values and judgements, and as the instrument to cope with authentic problematic situations, the topics of the learning materials were focused on Departure and Arrival situations that constituted two units. Taskbased was the basilica feature of the materials developed that was in keeping with each unit's task design in authentic situations use. More deliberately, each unit consisted of five lessons, which had set the objectives, tasks and assessment, and cover the topics of Overstaying, Imposing a penalty on overstaying, Passenger's passport is overdue, Rules and regulation report of Unit 1 Departure, and Passenger arrives without a visa, Making visa on arrival, Passenger's visa is expired, Dealing with arrival card and passport and Interrogating specific questions of Unit 2 Arrival. In order to be as closely as possible to resemble the authentic situations, Thai speakers and Chinese speakers were invited to record the conversation roles of officers and passengers respectively. Thus, based on Deterding's [13] study about the English pronunciation features spoken by Chinese speakers, each conversation stated out the features of words about syllable structure, consonants, and vowels and diphthongs accordingly.

Moreover, considering the double-shift working mechanism and no fixed time to learn English, they were interested in and inspired by learning English by using mobile devices, which should be free to use, easy to control, and friendly to follow. Thus, the researcher designed the learning materials supported by mobile devices based on all the needs from the officers, which was implemented in WeChat Public Platform, to lade the learning materials.

\subsection{Instructional manual}

Mainly based on the needs analysis and slightly referred to ฉิมลอย [14], the components of the materials (vocabulary, expressions, conversations and exercises, recordings) of the lessons and units developed, the structure of the lessons, and the layout and format of the lessons and units designed of the self-instructional materials were implemented in WeChat Public Platform. By the acronym name of ETAIPO, namely, English for Thai Airport Immigration Police Officers, the MALL materials aim at supporting the oral English proficiency of the officers. This part discuss about what ETAIPO is and how to use it in selfinstructional learning practice.

\subsubsection{What ETAIPO is.}


WeChat is a smartphone application mainly for message service use, which also supports users to create official accounts, called Public Platforms, to enable them to push new information or news to the users who subscribe to them. This study applied WeChat Public Platform to lade the English learning materials. Named after ETAIPO, the following figures display the main interfaces of this platform.

After subscribing to ETAIPO, users can enter this official account (Figure 1), and then can enter the homepage of ETAIPO as Figure 2.

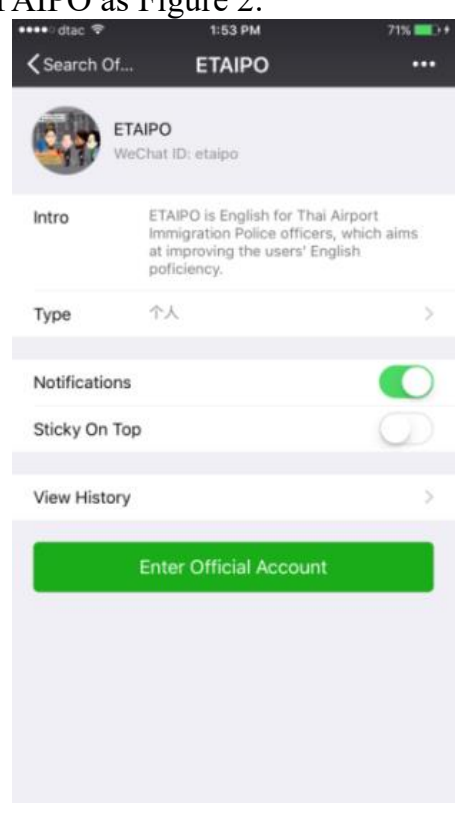

Fig. 1. Users can enter this official account.

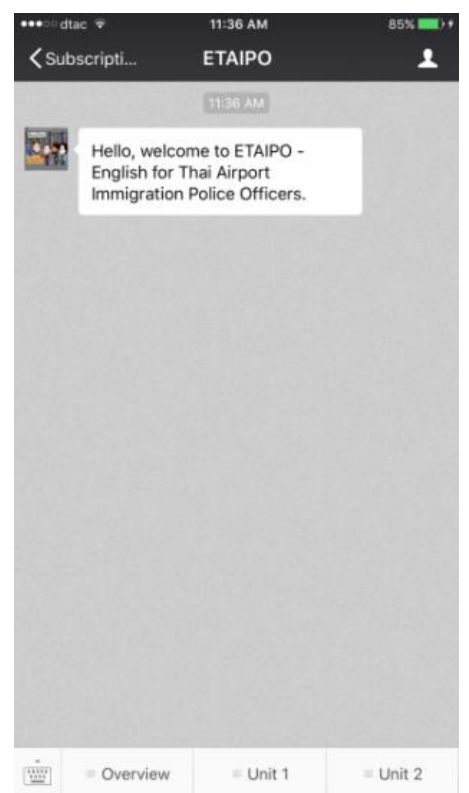

Fig. 2. 3 main menus on the bottom of the page ETAIPO. 
As displayed in Figure 2, ETAIPO has 3 main menus on the bottom of the page, Overview, Unit 1 and Unit 2. The first menu Overview embodies the Topics/Lessons, Objectives, Tasks and Assessment of each unit. The second menu Unit 1 and third menu Unit 2 each contains 5 lessons. Each lesson has 3 main sections: 1 Vocabulary and Expression, 2 Situation and conversation/Situation and report, and 3 Exercise.

How to use ETAIPO. Step 1: Install WeChat and search Official Accounts.

Users install WeChat application from App store. After log in WeChat, users should Add Contacts and search Official Accounts displayed in Figure 3.

Searching by typing 'etaipo', and Follow it, as displayed in Figure 4, then the users subscribe the official account successfully, and enter and use all the materials laded in this platform.
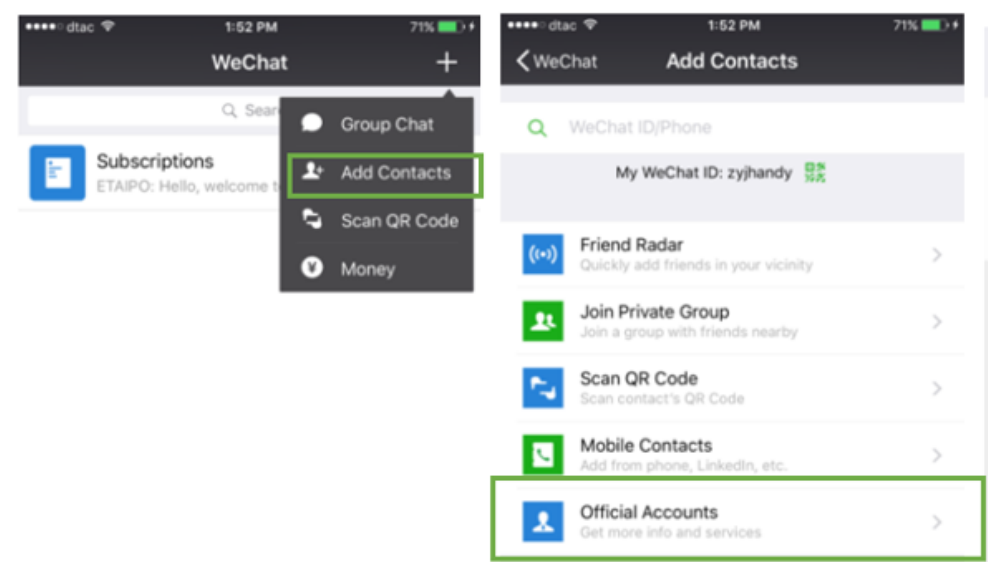

Fig. 3. Add contacts and search for official accounts. 


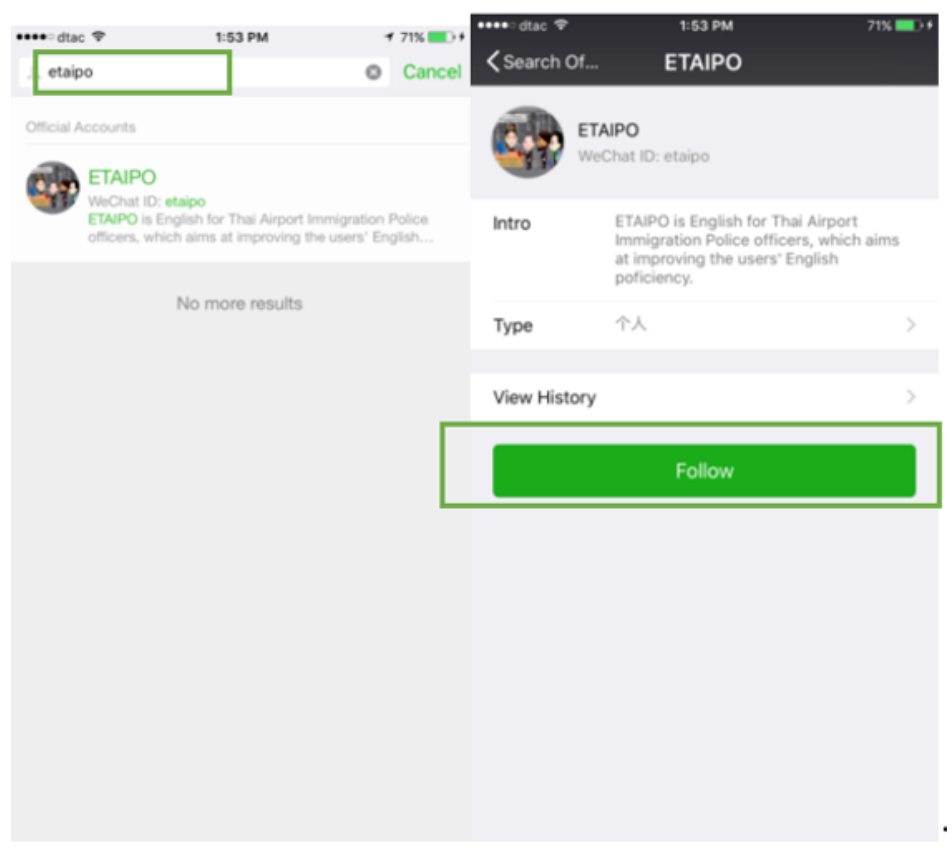

Fig. 4. Searching by typing 'etaipo'.

Step 2: Use the learning materials. ETAIPO contains 2 Units and 10 lessons as displayed in Chart 2.

Table 2. The 10 lessons in ETAIPO.

\begin{tabular}{ll}
\hline \multicolumn{1}{c}{ Unit 1 } & \multicolumn{1}{c}{ Unit 2 } \\
\hline Lesson 1 Passenger arrives without a visa & Lesson 6 Overstaying 1 \\
Lesson 2 Passenger makes visa on arrival & Lesson 7 Overstaying 2 \\
Lesson 3 Passenger's visa is expired & Lesson 8 Imposing a penalty on overstaying \\
Lesson 4 Dealing with arrival card and passport & Lesson 9 Passenger's passport is overdue \\
Lesson 5 Interrogating specific questions & Lesson 10 Reporting Rules and regulations \\
\hline
\end{tabular}

Next, Lesson 6 was introduced as an example to use the materials step by step, and the rest lessons are also can be operated by the introduced steps to learn.

In Figure 5, click Unit 2 and Lesson 6, then the set materials of Lesson 6 come up automatically. 


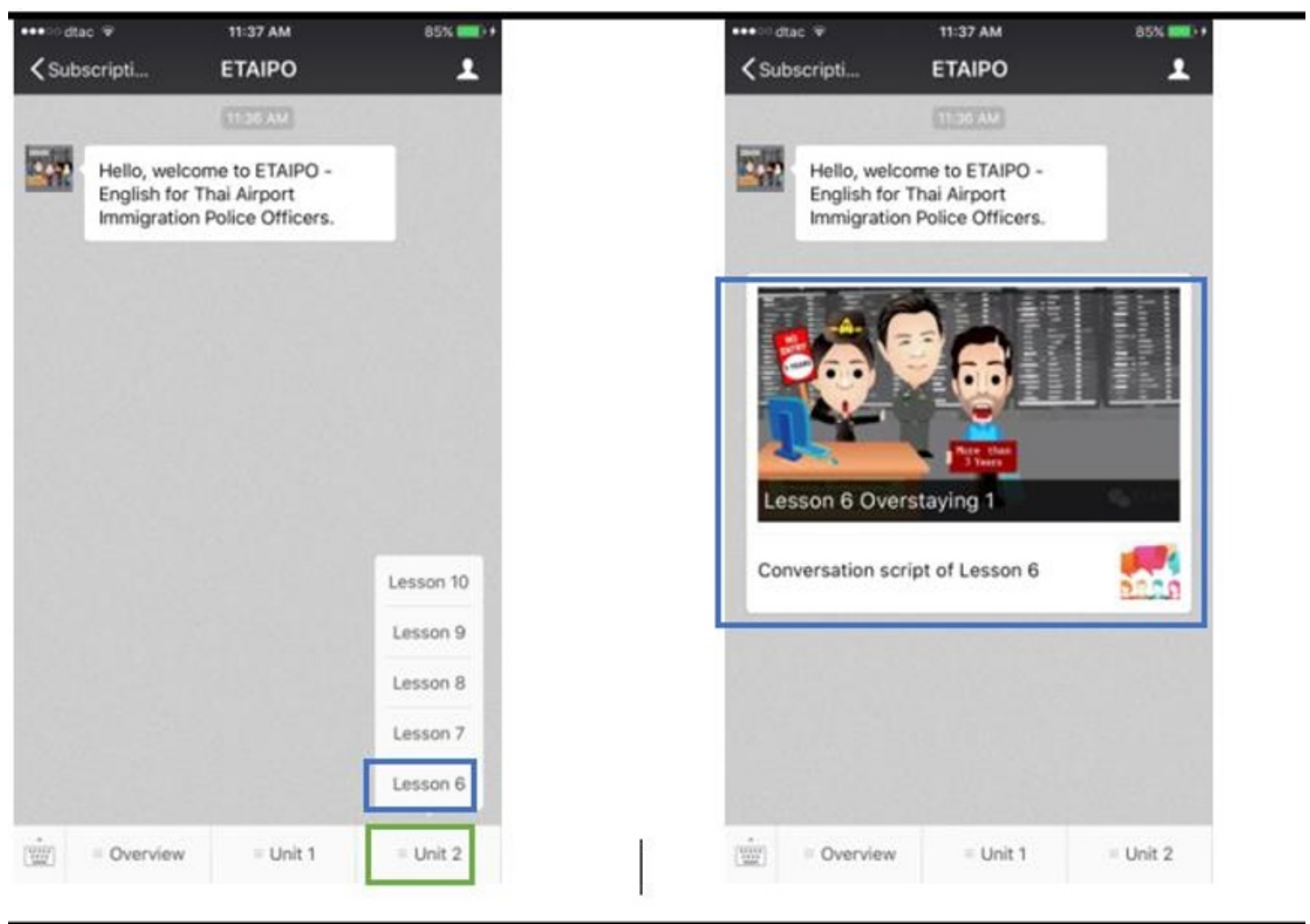

Fig. 5. Section "Module 2" and "Lesson 6".

Click Lesson 6 Overstaying 1, users can get into the interface of the whole lesson like figure 6.

Learn Vocabulary and Expression part by rolling down the page. The part of speech, pronunciation and word meaning are under each word. 


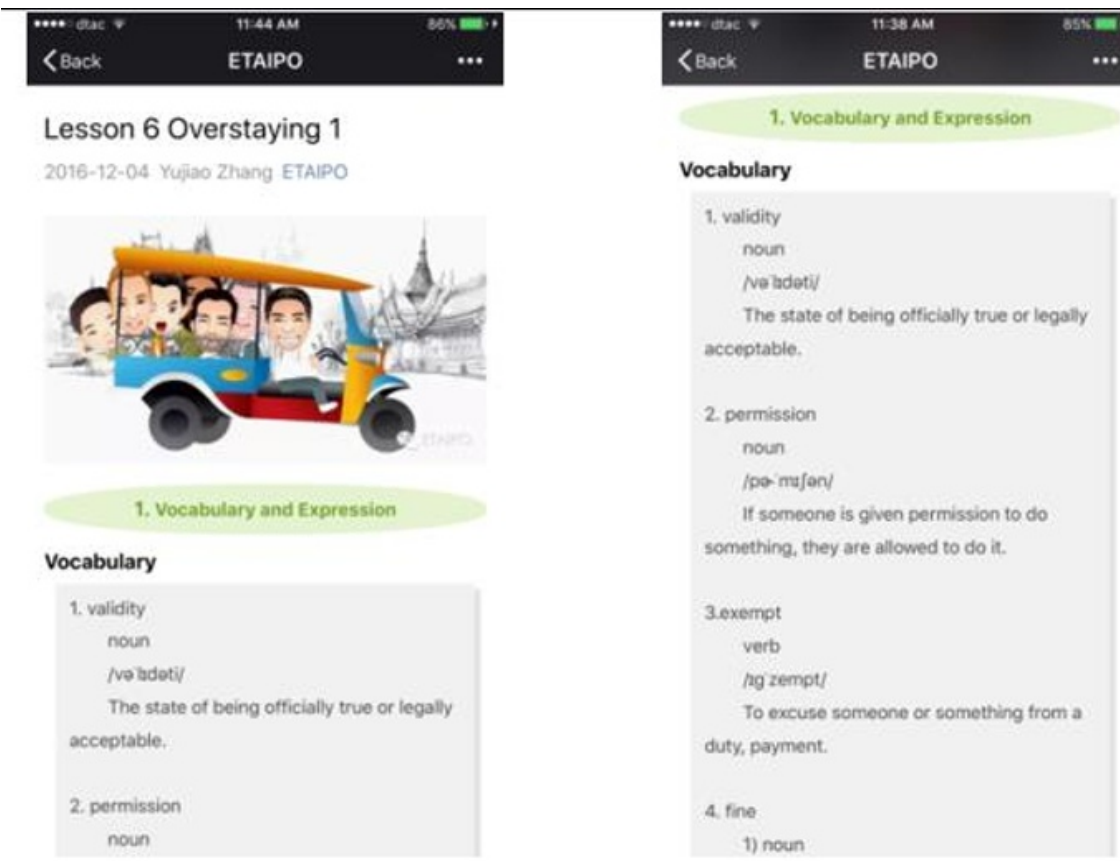

Fig. 6. The interface of the whole lesson.

Learn Situation and Conversation part, and listen to the recording by rolling down the page. The situation and the dialogue of the conversation (video) are developed as in Figure 7.

\begin{tabular}{|c|c|}
\hline $\cos \cos \%$ & $1138 \mathrm{AM}$ \\
\hline <Back & ETAIPO \\
\hline
\end{tabular}

2. Situation and Conversation

Situation

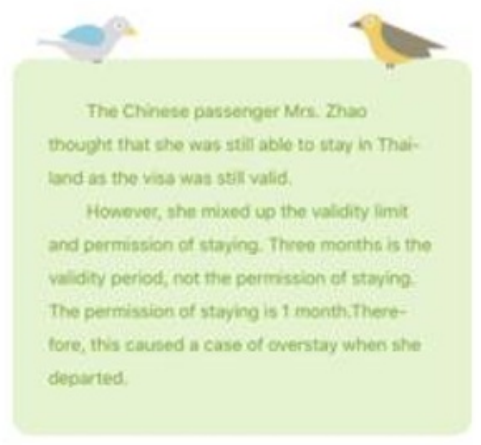

Conversation

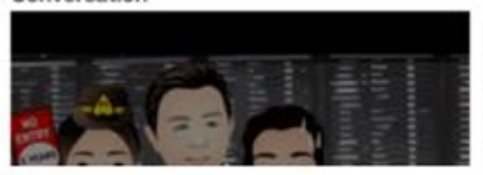

\begin{tabular}{|c|c|c|}
\hline$\cdots+\operatorname{arc} 4$ & $\operatorname{InSAM}$ & $55 \times=0$ \\
\hline <Back & ETAIPO & $\cdots$ \\
\hline
\end{tabular}

Conversation

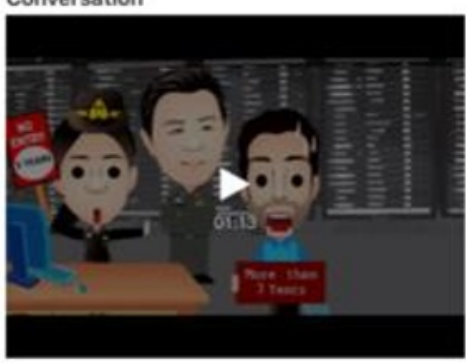

English Pronunication features of Chinese speakers

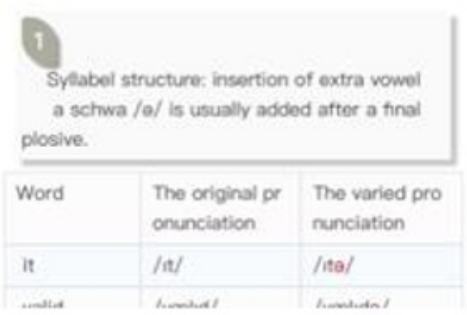

Fig. 7. Reversal of the situation and conversation in the dialogue format 
Get to know the English pronunciation features of Chinese speakers.

The relevant syllable structure, consonants and vowels of the words that are spoken by Chinese speakers are offered as in Figure 8, which are from the conversation of this lesson.
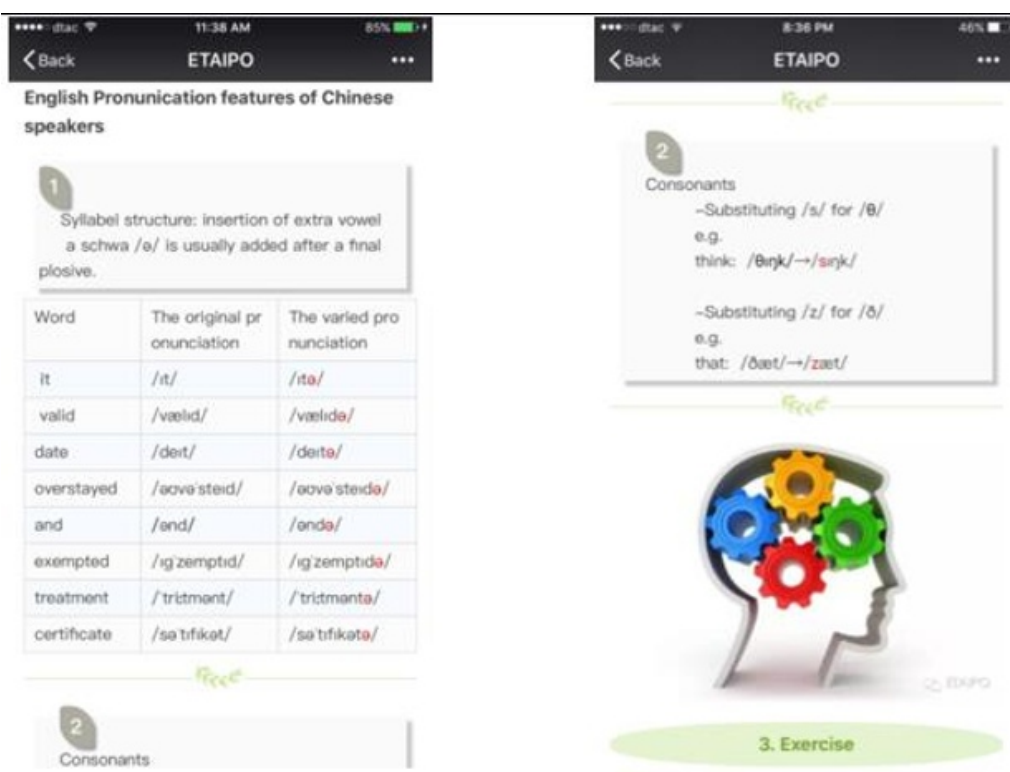

English Pronunication features of Chinese

ETAIPO

speakers

Syllabel structure: insertion of extra vowei Nosive.

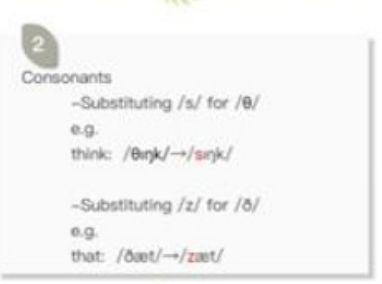

that $/ 0 \mathrm{ev} / \mathrm{h} / \mathrm{zat} /$

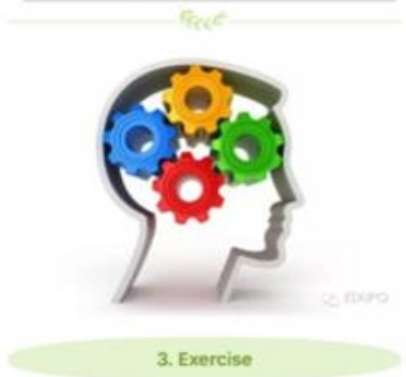

Fig. 8. Syllabic structure

Practice exercise:

3 questions are developed based on the conversation, and answers are provided below.

Online quiz: filling in the blanks.

After following the tips in Figure 9, a new page will lead to the online quiz interface, which is supported by ProProf.

After finishing the online quiz, the user can get a certificate and feedback as in Figure 10. 


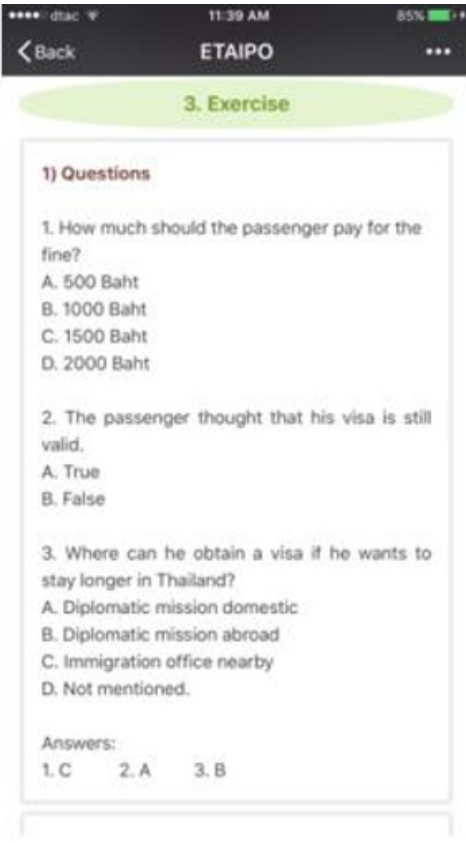

Fig. 9. Hints and interface of the online quiz
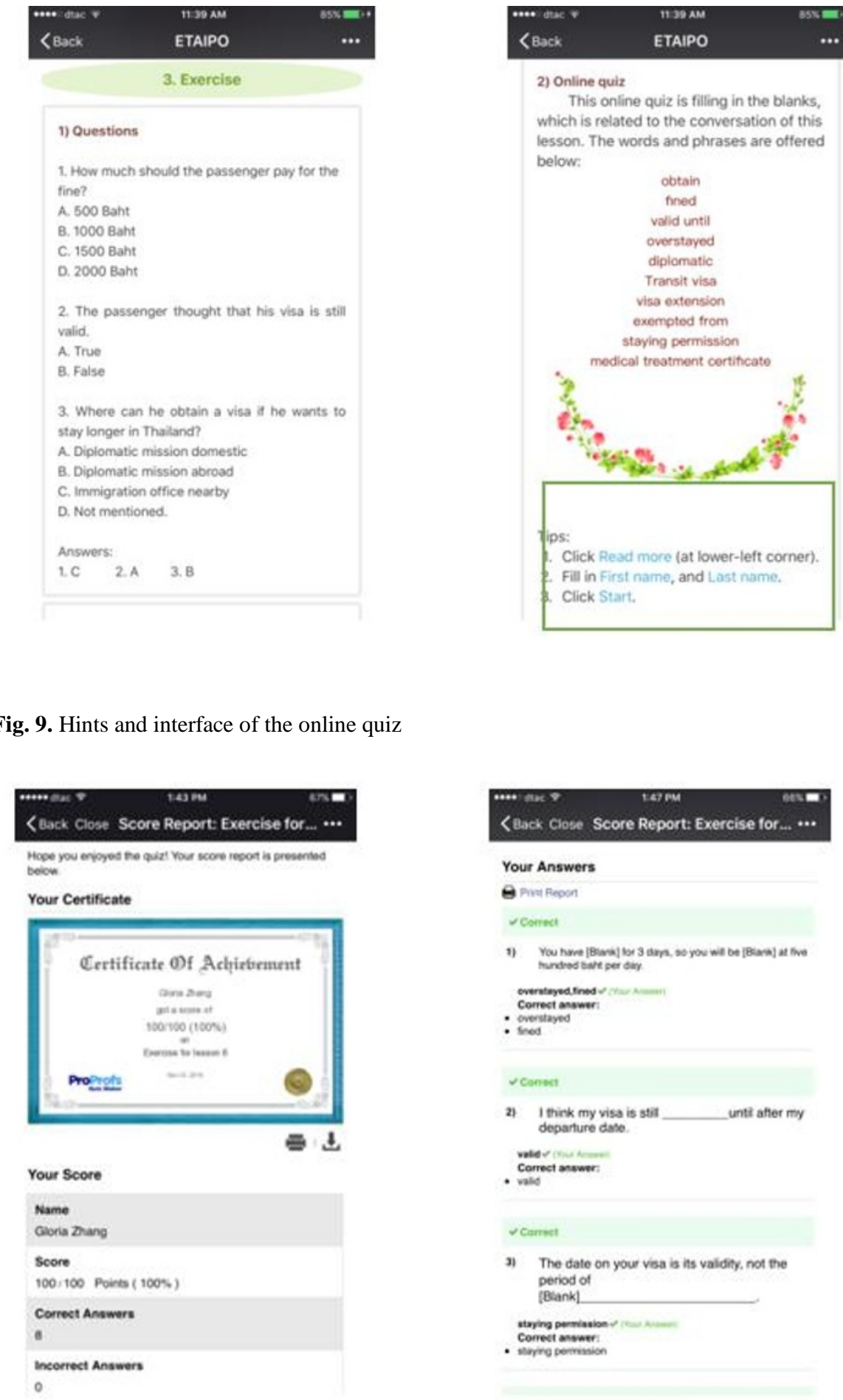

Fig. 10. Show certificate and revocation in the app 
In summary, users can get the information about the overview of each unit about the brief content, objectives, tasks and assessments. What's more, users can choose whatever lessons or content they want to start with. In each lesson, users can study the vocabulary and expressions, the conversations developed for every situation, or the rules and regulations related to immigration duties, listen to the dialogues recorded for each conversation, answer several multiple choices questions, and do online quiz by filling the blanks and get feedback with certificates.

\section{Materials validation and implementation}

In order to validate the content effectiveness of the materials designed, three experts from ELT field were invited to check the validity by applying IOC method, the form of which included 18 items that aimed at validating the content of the MALL materials developed concerning to the quality, the organization, and the presentation of the content, the use of the materials in the public platform in WeChat and the appropriateness of the recordings by rating the level of appropriateness with " +1 ", " 0 " or " -1 ". "+1" meant "the item is appropriate to be used, " 0 " meant "I am not sure" and " 1 " meant "the item is not appropriate to be used". The items were considered acceptable when the mean score $\bar{x}$ range from 0.5 to 1.0. Lesson 6 and Lesson 10 were offered for the experts to validate. According to the overall results from the IOC criteria, the overall mean score $\bar{x}$ was 0.98 , which meant suitable and accepted, and revealed that the materials developed had high content validity.

What's more, after validation, 4 airport immigration police officers were invited to experience the MALL materials for piloting test. After using the materials via WeChat public platform ETAIPO, the results indicated that the content, topics, interface, the platform, and recordings were all accordance with the officers' authentic situations at work, which were highly practical.

\section{Materials evaluation}

In order to explore the quality of MALL materials to support English oral communicative learning of Thai Airport Immigration police officers, a large-scale questionnaire survey was conducted with 68 immigration officers of Don Muang International Airport. There were 29 males and 39 females participated in this survey. The ages of them mostly ranged from 31 to 50 , and the majority of them had at least 4 years of experience in current positions. The interesting thing was that the mobile devices they used to learn the materials were mostly Apple and Samsung smartphones. What's more, the other mobile devices like Pads/Tablets, OPPO, HTC, Nokia, LG, Huawei, Sony and other smartphones were all being used by the participants, which revealed that this WeChat public platform ETAIPO had high compatibility that could be used at most mobile devices and operation systems.

Five-Likert scale was applied to assess the participants' opinions toward the MALL materials. After the hand-on practice of using the self-instructional MALL materials, the participants were asked to convey their opinions about the materials developed by ranking the numbers 5 to 1 with the statements designed for evaluation. 5 meant "strongly agree", and 1 meant "strongly disagree". From 5 to 1 , the degree of agreement decreased orderly. The overall mean score $\bar{x}$ was 4.36 , which indicated that the MALL materials had high quality of content, rational organization, pleasant presentation and convenient functions of the platform.

There were also comments from the participants. 1) It would be better if the pronunciation recordings could be offered for the vocabulary. 2) The contrast pronunciation recordings would be better offered in order to differentiate the differences between standard and Chinese 
speakers toward the varied pronunciation features of the words in each conversation. 3) English was the only language designed for the materials, which was a little bit difficult for the officers who didn't know much English at workplace. However, they also considered that these MALL materials were creative, interesting and convenient to learn. Different from the traditional paper materials, the most important aspect was that they could put the content learned from the materials into duty use immediately. Thus, they preferred to continue learn the MALL materials by using WeChat public platform only if they could have more content to learn, which was not only for duty purposes, but also for life-long learning.

\section{Discussion and recommendation}

The findings revealed that the self-instructional MALL materials that laded in WeChat Public Platform had high quality of content, rational organization, pleasant presentation and convenient functions of the platform for learning, which further indicated that the components of the MALL materials developed were proved to have comparatively content validity and be highly accordance with airport immigration duties, and certainly enhanced the airport immigration officers' English oral communicative learning that could be put into use immediately. Based on the authentic situations of English language use needed for duty purposes, being validated by ELT experts, and assessed by the officers' opinions after using, the MALL materials were implemented in WeChat Public Platform that used as a tool to study language, which is a feasible and practical innovation to support language learning and in line with Fernández-Pampillón et al. [16] and Rodriguez-Arancon et al's [17] criteria of Content quality, Capacity to generate learning, Motivation, Format and layout, Usability, Accessibility and Visibility of MALL to develop learning materials.

For the users who have free access to the MALL materials developed, it doesn't have time and place limitation since learning by using portable mobile devices is attainable whenever and wherever the users like. Being different with the traditional way of oral communicative learning, the MALL materials developed for this study have the potential to activate the users' interests, motivation and self-direction in order to cope with real work situations by following the lessons, objectives, tasks and assessments designed in ETAIPO that are in accordance with real targets and tasks in airport immigration duties, which assist the oral English vocabulary, expression and conversation use directly and immediately. By learning the MALL materials via mobile devices, the form of input in English language learning enriches the sensory experiences that both visual and auditory are involved at the same time.

To develop MALL materials for the target learners, conducting needs analysis versatilely is crucial. By conducting face to face interviews, the needs, lacks and wants could be explored in more depth. The more comprehensive and thorough the needs analysis is, the more extensive and radical the outcome will be. Beside the prepared questions, the researchers are suggested that they catch the random information delivered by the interviewers and make profound inquiry, which could be a feasible way make the interviews as well as the needs analysis more inclusive. Moreover, rationally applying the materials development framework, ADDIE model based on language and learning theories and principles to develop the materials is also of great importance. Analysis, design, development, implementation and evaluation are essential to construct the framework of developing materials to the target learners, which also need to be rationally in line with the special purposes or area connection in English language learning. After that, checking the validity of designed content by experts in the closely related area is highly practical especially for the new researchers. However, Content validity check by experts also can't avoid potential subjective opinion. Thus, researchers are suggested that they design the IOC form precisely and use more objective language in expressions. Concerning to the evaluation of the materials, researchers better 
develop the questionnaire with clear and progressive question items and highly related with the designed materials to ensure that the results are highly reliable to ensure the and effectiveness of the materials.

This paper also has some limitations. Beside the technical limitations of WeChat application, the content developed was mainly dealing with the oral communication problems between the officers and Chinese speaking passengers, which couldn't be applied to solve all the general difficulties with overall situations at work. Thus, the researcher recommended that in order to thoroughly work out the all-sided needs of the airport immigration officers, a fully scale of further study that could be applicable to all cases should be developed.

\section{References}

1. A. Aaflu, A. Nazarov, Paper presented at the E3S Web of Conferences, 208 (2020)

2. D. Crystal, English as a Global Language (Cambridge University Press, 2003)

3. Tourism Authority of Thailand (Tourist Nationalities, 2015)

4. M. S. Knowles, S. Malcolm and Associates, Andragogy in Action: Applying modern principles of adult education (Jossey Bass, 1984)

5. C. Detaramani and S. I. Chan, RELC Journal, 30(1), 124 (1999)

6. L. Dickinson, Self-instruction in language learning, (Cambridge University Press, 1994)

7. J. C. Richards, Curriculum Development in Language Teaching, (Cambridge University Press, 2001)

8. B. Tomlinson, Applied Linguistics and Materials Development (Bloomsbury Publishing, 2013)

9. Y. Wang and L. Wu, Fourth International Conference on Intelligent Systems Design and Engineering Applications (2013).

10. Y. M. Huang, S. H. Huang, Y. T. Lin, Computers and Education 58, 273 (2012)

11. The ADDIE Model: Instructional Design, Educational Technology, http://educationaltechnology.net/the-addie-model-instructional-design/, 2014.

12. D. Deterding, English World-Wide, 27(2), 175 (2006)

13. T. Hutchinson, A. Waters, English for Specific Purposes: A learning-centered approach (Cambridge University Press, 1987)

14. K. Johnson, Communicative Syllabus Design and Methodology (Pergamon -Oxford, 1982)

15. J. C. Richard, T. S. Rodgers, Approaches and Methods in Language Teaching (Cambridge University Press, 2003)

16. A. Fernández-Pampillón Cesteros, E. Domínguez Romero and I. Armas Ranero, Herramienta de Evaluación de la Calidad de Objetos de Aprendizaje: Guía para la producción y evaluación de materiales didácticos digitales (Universidad Complutense 2012)

17. R. Rodriguez-Arancon, J. Ariis-Hita, C. Calle-Martinez, lETC -2013 (2013). 